\title{
Rihanna Works Her Multivocal Pop Persona: A Morpho-syntactic and Accent Analysis of Rihanna's Singing Style
}

\author{
LISA JANSEN AND MICHAEL WESTPHAL
}

Pop culture provides rich data that demonstrate the complex interplay of World Englishes

\section{Introduction}

Singing is a very dynamic and innovative mode of communication through which artists often express themselves with a set of various voices. Today, pop music circulates across national boundaries and English is the main medium of communication in transnational pop culture. In this special context different varieties of English meet at a high density. Rihanna's single Work is an example of this prevalent multivocality in pop music culture. Her language performance attracted public attention of various sorts as she audibly incorporates several Caribbean English Creole (CEC) features. While some critics describe her lyrics as 'gibberish' (cf. Noelliste, 2016), others acknowledge her performance as a 'reclamation of her Barbadian heritage' (Gibsone, 2016). The example of Rihanna shows that singers can be transporters of English varieties: she is a Caribbean artist who started a successful career in the US, and whose music today has global reach. Singers, like Rihanna, are thus mobile, transnational linguistic agents. On the one hand, she physically travels the world playing concerts to her audiences. On the other, her persona, music, videos, and further media commodities are part of the global 'mediascape' (Appadurai, 1996). In other words, her products easily spread across the globe and are reproduced, transcending national and social boundaries. New technologies (e.g. smart phones, tablets) and applications (Facebook, Twitter, Instagram) facilitate as well

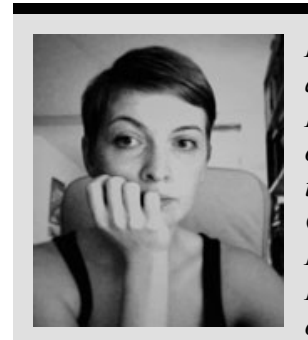

LISA JANSEN is a lecturer and doctoral candidate at the English Department (Chair of Variation Linguistics) of the University of Münster, Germany. She completed her $M A$ degree in English, French, and Art History. Her ongoing PhD research

focuses on the perception of and attitudes towards linguistic performances in music. Further research interests include the sociolinguistics of performances and/in globalization, perceptual dialectology as well as language and identity. Email: lisa.jansen@wwu.de

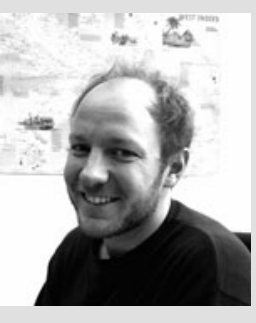

MICHAEL WESTPHAL is post-doctoral researcher at the Chair of Variation Linguistics at the English Department of the University of Münster, Germany. In spring 2016, he completed his PhD project 'Linguistic Variation in Jamaican Radio' at the University of Münster. He also studied and conducted research at the University of the West Indies in Mona, Kingston, Jamaica. His research interests include varieties of English with a focus on the Caribbean, language attitudes, variational pragmatics, and language in the media.Email: michael.westphal@wwu.de 
as accelerate the transnational dissemination of media resources. Moreover, singers show that the linguistic (and cultural) resources as such are mobile. Different language influences are formed into individual linguistic repertoires. Singers often playfully employ certain features to highlight parts of their identity or locate themselves in a particular music genre.

In the last decades sociolinguists have acknowledged that performed language, such as singing, puts transcultural and translinguistic flows on display (Pennycook, 2007). Studies so far have focused on performed accents, hence mainly investigating pronunciation features. We aim to show the complexity of language performances for the highly salient example of Rihanna's Work, which inevitably also includes the analysis of morphosyntactic features. This case study does not only reveal the constituent parts of Rihanna's multivocal persona, but also provides insight into the sociolinguistic interaction of the varieties of English.

\section{The Sociolinguistics of Singing}

\section{Performed Language}

Singers are performers. They are constantly projecting a persona (Coupland, 1988: 139), which is the displayed figure the audience perceives. It can be more or less in congruence with the private person behind the artist, but is still a publicly performed character. Singing, the most crucial and defining part of this projection, is described as 'high performance' (Coupland, 2007: 146-176) because such language performances are planned and rehearsed, stylized communicative events. They are produced explicitly for an audience with the aim of entertaining. Along with other modalities such as fashion or music videos, language and specifically ' $[\mathrm{a}] \mathrm{ccent}$ is perhaps the most obvious means by which performers index identity' (Bell \& Gibson, 2011: 570) and hence build and maintain their persona. The study of music - or more precisely, of the employment of a specific accent in singing - thus gives insight into the mechanisms of linguistic identity formation.

\section{Two Trends: American and Going Local}

When reviewing sociolinguistic works on the stylisation of accents in singing, two main trends are observable: singers either adopt an 'Americanized' singing style or they 'go local'. Trudgill's seminal study (1983) is commonly considered the starting point for researching the sociolinguistics of singing. $\mathrm{He}$ notices that many British artists from the 1950s up to the mid-1970s emulated a somewhat American accent and sets out to investigate possible motivations for this language behaviour. This stylized American accent is characterized by a set of five sound patterns which are supposedly most characteristic of American speech: intervocalic /t/ in better as [r] or [d] instead of [t] or [?]; post-vocalic /r/ as in girl or more; BATH in dance or half as [æ]; PRICE vowel in life as monophthong [a:]; LOT vowel in body as unrounded [a:]. This so-called USA-5 model (Simpson, 1999: 345) is a constructed, perception-based accent. Its features do not occur altogether in one single American accent in the US. Trudgill's analysis shows that the actual singing style, rather than being entirely 'American' is better described as a 'hybrid accent' characterized by a mixture of British and prototypical American (and Southern or African American) features. Following LePage and Tabouret-Keller (1985; Trudgill, 1983: 155), ${ }^{1}$ he ascribes this mixture to acts of conflicting identities which represent singers' multiple affiliations and competing motivations: on the one hand, the US is the cradle of modern pop and rock music. American artists have dominated the music landscape and became role models for other musicians who in turn converged towards them (Trudgill, 1983: 144). On the other hand, the singers analysed are Britons. Moreover, British bands have established themselves as an authority within the music industry (initiated by the Beatlemania) and expressed this new self-perception and self-confidence linguistically. While the use of American features declined, British features, predominantly from working-class accents, gained popularity, especially with the emergence of British Punk music in the mid-1970s (Trudgill, 1983: 154ff).

Simpson (1999: 350-354) adds Halliday's (1978) concepts of tenor, field, and mode of discourse to the discussion. He shows that these artist-specific aspects are crucial for the performer's choice of style and hence add to the complexity of motivations. Their language behaviour is strongly influenced by persona (tenor) and lyrical content (field) which both might demand taking on an alter ego's voice. Additionally, singing-inherent influences (mode) determine the intensity of style-shifting. While performing, an artist can include different modes such as singing or speaking. The more a singer approaches the speaking mode, the closer will the performed accent be to his/her vernacular voice (Simpson, 1999: 360).

More recent studies show that the trend of 'going local' observed by Trudgill perpetuates in modern music and especially in specific genres such as 
indie rock and pop, punk, hip hop, or reggae. These are strongly intertwined with subcultural flows that often entail e.g. certain social backgrounds, political views, clothing styles, and linguistic choices which are regarded appropriate for a genre (Trudgill, 1983: 143-144). O'Hanlon (2006) is the first to have observed a shift in the associations of singing accents. While most music genres in Australia seem to follow the 'ubiquitous American pronunciation model' (O'Hanlon, 2006: 202), Australian hip hoppers do not accommodate but instead stick to their local voice. They 'keep it real' by taking pride in their origins and upholding a close connection with their target audience. Pennycook (2007) shows that such localized versions of hip hop can also be found in EFL (English as a Foreign Language) countries such as Japan. Beal (2009) investigates the British indie rock band the Arctic Monkeys and shows that their frontman sticks to his 'natural voice' by exclusively using Sheffield features. The band is well-known for their strong identification with their home city. Beal explains that the associations triggered by the Americaninfluenced singing style have changed throughout the decades. Since it has become virtually omnipresent in popular music, it does not evoke the association 'American' or 'Americanness' anymore, but instead indexes 'mainstream music' (Beal, 2009: 226, cf. Gibson, 2010). ${ }^{2}$ This way of singing has become so well-entrenched that it is the default mode for many popular music genres (Gibson \& Bell, 2012: 160). This also leads to the assumption that this 'mainstream singing accent' is more marketable and reaches a broader audience, which in turn results in financial success. The case of singers 'going local' is an active choice against an American-influenced mainstream and towards linguistic and creative independence and authenticity (Gibson \& Bell, 2012: 141).

\section{Rihanna's Pop Culture Persona}

28-year-old Rihanna is a born and raised Barbadian singer-songwriter of international recognition. With support of music producer Evan Rogers she recorded demo tapes which, after an audition, eventually led to DefJam Recordings, an American hip hop label, signing her on a six-album contract in 2005. She introduced herself linguistically as a Caribbean artist with her debut single Pon de Replay. The title itself contains two CEC features: the preposition pon for on and TH-stopping in de. Since then Rihanna has become one of the most successful solo artists worldwide. Her music accolades include many number one hits in the US and other countries, selling more than 200 million tracks worldwide, as well as numerous awards (rihannanow.com). Rihanna is known for repeatedly reinventing her persona musically and fashion-wise. She switches and mixes genres ranging from reggae and dancehall, through hip hop and R'n'B, and to rock and electro dance music. Her collaborations with renowned artists from various music genres demonstrate this musical versatility: reggae and dancehall performer Elephant Man, US hip hop artists Jay-Z and Eminem, R'n'B star Chris Brown, and Scottish rock band Coldplay, just to name a few. The influencing genres above are also associated with specific performance codes: US hip hop is strongly connected to African American English (AAE), reggae and dancehall singers often include Jamaican or more broadly CEC features, whereas rock and dance mostly use Standard American English (StAmE). Although Rihanna reports that when moving to America she had to 'adjust her accent' (TheCelebFactory, 2012) towards an American model in order to be properly understood in interviews and doing official business, she turns out to be versatile linguistically as well. Rihanna incorporates resources from both her musical influences and corresponding linguistic styles to represent and perform her pop-culture identity. Her persona is more than a displayed character created by herself alone. It is composed and influenced by a list of people who are part of the production process (cf. Eberhardt \& Freeman, 2015: 313). In Work she collaborates with various artists from different musical and ethnic backgrounds. Among her co-writers are hip hop and R'n'B artists and producers from Canada with Jamaican roots, white as well as African Americans. Her co-performer, Drake, is a Canadian artist with African-American and Jewish-Canadian roots. Along with Rihanna, seven artists are credited with creating the single Work. All of them are part of constructing and presenting Rihanna's persona in this single.

\section{Analysing Rihanna's Multivocality in Work}

Rihanna's Work is a multilayered piece of art on different levels of modality. Content-wise the song addresses different levels of work: a) working relentlessly for a career and its consequences for a personal life, b) putting work into a romantic relationship, or c) the work that is put into fulfilling sexual desires. On a linguistic level the single fuses different varieties of English which represent 
Rihanna's transnational pop culture persona. All examples given in the text below refer to the transcription of the song in the appendix.

\section{Morpho-syntactic and Accent Variation}

We analyse Rihanna's multivocal linguistic performance in Work both on a morpho-syntactic and on an accent level. Bell \& Gibson (2011: 570) stress the central role of accent for performances and most sociolinguistic research on music has focused on pronunciation (e.g. Trudgill, 1983; Simpson, 1999) while only more recent corpus studies (e.g. Werner, 2012; Kreyer, 2015) have investigated morpho-syntactic variation in pop songs. However, research on linguistic variation in hip hop (e.g. Lee, 2011) has shown the benefits of including different structural levels of variation in linguistic research on music. In order to illustrate the mixture of different varieties of English in Work we identify individual salient features which are typical of specific varieties. In his analysis of performed language in New Zealand broadcasting Bell shows the benefits of such an approach as a successful language performance is often 'more a matter of individual occurrences of salient variables than of quantitative summings and relative frequencies' (1992: 336).

In contrast to other songs by Rihanna, Work includes numerous typical morpho-syntactic features of CECs (Kortmann \& Lunkenheimer, 2013; Hackert, 2012): the use of $n a$ as a negator, copula absence (line 10: you na righteous); the absence of the inflection $\{-\mathrm{s}\}$ on third singular verbs (line 3: he see); the personal pronouns me and him in subject position (line 6: me na care if him hurt); modal auxiliary hafi (line 2: me hafi work); quotative se (line 2: he se me hafi work); and the progressive construction $a$ go which indicates prospective future meaning (line 5: when you a go learn). While some of these features, such as the future marker $a$ go, are shared by most CECs, including Barbadian Creole/Bajan (Denny \& Belgrave, 2012) which is the local vernacular of Rihanna's home country Barbados, all of them are typical of Jamaican Creole (JC) (Patrick, 2008). JC is the most well-known Creole variety of the Caribbean and is 'one of the globally relevant contact vernaculars' (Mair, 2013: 264) mainly due to the world-wide success and spread of reggae and dancehall music. However, it is not possible definitely to attribute specific features to JC or Bajan because for instance copula omission and third person singular $\{-\mathrm{s}\}$ absence are also typical of AAE (Wolfram, 2008). Rihanna does neither consistently nor exclusively use CEC grammar but switches back and forth to Standard English morpho-syntax: she uses Standard English case sensitive pronouns (line 26: I mean who am I to hold your past against you; line 14: You took my heart on my sleeve for decoration), inflections on verbs (line 27: I just hope that it gets to you), copula (line 30: I'm trying babe), and negation with do support (line 23: Don't leave me stuck here in the streets). Thus, the morpho-syntactic variation positions Rihanna's multivocal persona in between CEC (most likely Bajan and JC) and StAmE. AAE is another possible influence but Rihanna does not use any morpho-syntactic features exclusive to AAE, only the two features mentioned earlier shared with CEC.

Rihanna's accent variation in Work also shows a diverse linguistic repertoire and allows for an even more fine-grained differentiation of linguistic varieties. Similar to the morpho-syntactic level her accent in Work is strongly marked by several features typical of Caribbean English and CEC (Roberts, 2007): monophthongization in FACE (line 12: adoration; line 13: patience; line 14: decoration; line 15: foundation); word-final $(-\mathrm{t},-\mathrm{d})$ consonant cluster absence (line 9: dealt, nicest, 11: text, 19: act); and TH-stopping, i.e. the realization of TH as an alveolar stop (line 15: with, the). The latter two features are also typical of AAE (Edwards, 2008) but again there are no accent characteristics exclusive to AAE in Work. Furthermore, her accent is marked by word-initial H-deletion (lines 6, 7, 8: him; line 6: hurt), a salient feature of JC which distinguishes it from other varieties in the region. Yet again, her performance varies between realizations of non-standard varieties and a StAmE pronunciation (Kretzschmar, 2008): for example, she retains word-initial $\mathrm{H}$ in heart (lines 13, 14), hold (line 26), and hope (lines 27, 28, 29), realizes $\mathrm{TH}$ as an interdental fricative in that (lines 16, 17, 18) and this, retains consonant clusters in believed (line 12) and don't (lines 22, 23), and realizes FACE with an upgliding diphthong in baby (line 22), babe (line 30), and say (line 30). Her accent is also marked by features of the USA-5 model: she deletes /t/ in wanted (line 16), she realizes the two BATH tokens chance (line 24) and past (line 26) as [æ] as well as the LOT vowels in all (line 12 and 16) and wanted (line 16) with an unrounded fronted vowel. She monopthongizes the PRICE vowel in recognize (line 30). In words such as like (line 8) and nicest (line 9) she also shows the tendency to elongate [a], although this partial monphthongisation can also result from singinginherent modifications (Coupland, 2011: 575). 
Apart from in never (line 17) her accent is consistently rhotic, which is a further characteristic of StAmE but also of Bajan, the only fully rhotic Creole in the Caribbean (Wells, 1982: 570). Particularly in the chorus Rihanna's pronunciation is marked by a high degree of nasalization and an under-articulation of consonants, two further features which together produce a typical Bajan sound pattern (Roberts, 2007: 96-97). Furthermore, Rihanna realizes act and it (line 8) with a glottal stop, another salient characteristic of a Bajan accent (Wells, 1982: 584).

The analysis shows that Rihanna's performance varies mainly between CECs, mostly JC and Bajan, and StAmE while AAE is another potential influence given her hip hop affiliations. This multivocal variation is not expressed randomly, but reveals certain patterns. Some passages in the song correlate more intensely with a Caribbean English voice while others lean towards an American English sound. Bajan accent features occur most densely in the chorus. Through the repetitive structure of the chorus the individual words 'blur into each other', which results in assimilation of sounds and the elision of word-final consonants: this reinforces the Bajan impression. The CEC accent and morpho-syntactic features occur most consistently in the chorus and the first verse. Rihanna's Caribbean voice leans more towards speaking and sounds rather mumbling and blurred in these parts of the song whereas her singing style is very clear in the last two verses, which are mainly produced with a StAmE accent. On a content level, these last two verses focus on the work put into romantic relationships, whereas the chorus and the first verse are more ambiguous as they address career aspects of work with sexually loaded metaphors. This distribution shows that while Rihanna uses many different varieties of English in her performance, she does not blend them completely: Rihanna's multivocal persona is constructed by the co-existence and only partial overlap of diverse linguistic features from different varieties of English.

\section{Other Levels of Modality}

On a musical level Work is similarly complex and rich in influences as Rihanna's linguistic choices. It combines elements from Jamaican dancehall, pop music, contemporary R'n'B, and hip hop. This both multivocal and at the same time 'multimusical' impression is supported and even strengthened by the song's visual representation. One of the two videos produced for this song is set in a Caribbean restaurant in Toronto, called The Real Jerk, and portrays a dancehall event. Rihanna, at the centre of attention, is staged as a 'Jamaica Dancehall Queen' (Carlos, 2016). The setting is dominated by the traditional pan-African colours black, red, green, and yellow which are strongly associated with the Caribbean or, more precisely, Jamaica, reggae, and Rastafari. Rihanna and others are performing typical dancehall queen moves such as wining, i.e. 'dance erotically by swinging the hips vigorously while thrusting the buttocks back and forth' (Allsopp, 2003: 606). Men and women are joined in well-known, practiced dancehall move routines. We see Jamaican (Red Stripe) and Trinidadian (Carib) beer brands and the preparation as well as smoking of marihuana cigarettes. Also, jerk chicken - a Jamaican specialty - is being served in the background. In comparison, the other video version is free from any Caribbean references - except maybe Rihanna's wining moves, but those can be seen in many videos by other non-Caribbean artists as well.

\section{Rihanna Works Her Co-existing Identities}

In her single Work Rihanna mixes different linguistic and cultural identities to underline and express her multivocal pop music persona. Trudgill (1983) describes this kind of hybrid accent as a result of 'conflicting identities.' Our analysis, however, shows that in Rihanna's case it is more appropriate to speak of 'co-existing' identities. She seems to consciously and skilfully play with the linguistic resources that reflect certain parts of her identity and represent different musical genres. Rihanna combines two trends: she goes both local and American. The analysis detects Bajan and JC (or more generally CEC), StAmE, and possibly AAE features on an accent and morpho-syntactic level. Her use of different varieties of English is inconsistent, but not unstructured. The observable correlation between the choice of variety(/ies) and specific parts in the song can be explained with the different degrees of singing (modes of discourse) Rihanna exhibits in certain passages. Following Simpson (1999), singing-inherent influences play a role in singers using their vernacular voice in rather spoken passages and an American-influenced style when singing. In Rihanna's case, the closer she gets to the speaking mode the stronger her Caribbean background determines the voice. The higher the degree of singing, the more she accommodates to an American singing-style. This distribution of varieties also corresponds to the content of the song 
(field of discourse): she uses StAmE for expressing the romantic aspect of love while her Caribbean voice describes work in a more sexually suggestive way. The language performance and the video exoticize and sexualize the Caribbean.

Public reactions show that Work stirred up attention. Especially the typically Bajan tendency towards nasalization and under-articulation of consonants led everyday listeners to dismiss Rihanna's singing as unintelligible and 'gibberish.' Additionally, many of the CEC morpho-syntactic features might not be very prominent and easily intelligible for non-CEC speakers. Therefore, the use of StAmE features may also indicate Rihanna's intention to address her main target audience, which is perhaps not wellversed in CEC. Switching back and forth between CEC and StAmE features allows her to express her Bajan identity while at the same time being intelligible for an international audience. Nevertheless, the impression that Work is devoted to her Caribbean roots prevails. Some salient features that have been established by reggae musicians over decades clearly trigger associations of 'Caribbeanness.' Additionally, the 'dancehall video' straightforwardly evokes further typical Caribbean modalities and complements the linguistic observation. Her Bajan features, on the other hand, probably appeal to no more than a small in-group of Bajan speakers.

Pennycook (2007) and others (e.g. O'Hanlon, 2006; Gibson, 2010) have mostly concentrated on locally popular bands when investigating language trends and shifting indexicalities in music. Rihanna, however, is a transporter of English varieties on a different scale. She is a multifaceted mainstream artist, a fashionable pop persona and global player. Her language performances are

\section{work work work ajebebnslsnwbwjwpajdb work work work adbejwkwbsbdbjdjs dur dur dur}

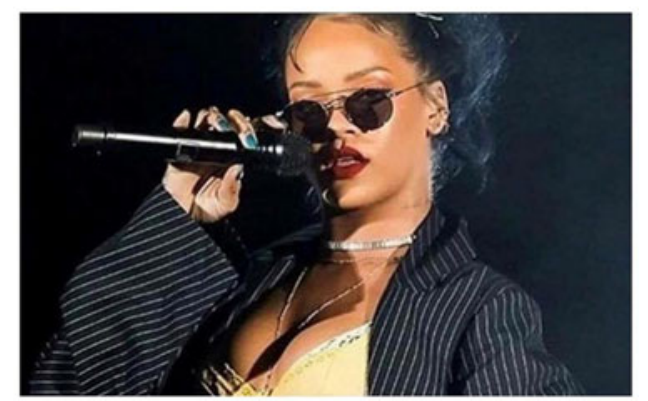

Figure 1. Meme about Rihanna's performance in Work ${ }^{3}$ determined by her multilinguistic background and ethnic roots. Her products, such as the single Work, are part of the mediascape and, due to her persona's popularity, have global reach. They give insight into the dynamics of global Englishes. Especially in music vernacular varieties such as JC or AAE gain worldwide reach and prestige (Mair, 2013: 256, 264). Public reactions show that only insiders - mostly CEC speakers - recognize and appreciate her Caribbean voice. Others comment and mock Rihanna's voice via social networks and other mainstream media, or add e.g. memes to the discourse. Blommaert defines memes as 'a particular multimodal semiotic genre of online discourse - an image accompanied by a caption - specifically made for virality' (2015: 18). The popular meme below (Figure 1) shows that the specifically Bajan-sounding parts with CEC morpho-syntax of Rihanna's performance are unintelligible to many listeners and even equalled to a nonsensical sequence of sounds. Clearly, this meme does not only make fun of Rihanna's singing style; it also shows the audience's ignorance towards her Bajan accent CEC morphosyntax and its misinterpretation as 'gibberish' (cf. Noelliste, 2016).

Sociolinguistic research on the language of globalization and World Englishes should emphasize the importance of popular culture products and their interplay with sociolinguistic change. They show a very dense co-existence of different varieties and styles. Such cultural products have the potential to reach global audiences and give linguists the opportunity to study effects and reactions by listeners, e.g. by studying public reactions and attitudes in the media. Such language performances, creative, poetic, and consciously produced, are less constrained by national borders, speech communities, and standard language ideologies than other communicative contexts. Thus data from transnational pop culture, e.g. unique performers' voices as well as people's reactions in response to them, open up a small window which gives insight into the global variation of English today.

\section{Notes}

1 LePage and Tabouret-Keller (1985) analyze linguistic choices of individuals particularly with respect to multilingual communities, giving insight into the speaker's language behaviour towards a linguistic model. They describe a multilayered situation of conflicting identities in which language use is modelled after the group/s speakers want to identify with.

2 Gibson (2010) confirms that also for New Zealand singers the American-influenced singing accent has 
widely become the default pronunciation when performing.

3 The meme about Rihanna's performance in Work was retrieved from http://www.dazeddigital.com/ music/article/30102/1/rihanna-s-patois-and-your-misinformed-memes, 28. Oct. 2016.

\section{References}

Allsopp, R. 2003. Dictionary of Caribbean English Usage. Kingston: University of the West Indies Press. [reprint; first published by Oxford University Press in 1996]

Appadurai, A. 1996. Modernity at Large: Cultural Dimensions of Globalisation. Minneapolis: University of Minnesota Press.

Beal, J. C. 2009. “'You're not from New York City, you're from Rotherham": Dialect and identity in British indie music.' Journal of English Linguistics, 37(3), 223-240.

Bell, A. 1992. 'Hit and miss: Referee design in the dialects of New Zealand television advertisements.' Language and Communication, 12(3/4), 327-340.

Bell, A. \& Gibson, A. 2011. 'Staging language: An introduction to the sociolinguistics of performance.' Journal of Sociolinguistics, 15(5), 555-572.

Blommaert, J. 2015. 'Meaning as a nonlinear effect: The birth of cool.' In T. Lillis (ed.), Theory in Applied Linguistics Research: Critical Approaches to Production, Performance and Participation. Amsterdam: Benjamins, pp. 7-27.

Carlos, M. 2016. 'Rihanna works, works, works her Caribbean style all over her new video.' Online at $<$ http://www.vogue.com/13404737/rihanna-draketommy-hilfiger-jamaica-dancehall-queen/> (Accessed April 13, 2016).

Coupland, N. 1988. Dialect in Use: Sociolinguistic Variation in Cardiff English. Cardiff: University of Wales Press.

Coupland, N. 2007. Style: Language Variation and Identity. Cambridge: Cambridge University Press.

Coupland, N. 2011. 'Voice, place and genre in popular song performance.' Journal of Sociolinguistics 15(5), 573-602.

Denny, S. \& Belgrave, K. 2012. 'Barbadian Creole English (Bajan).' In B. Kortmann \& K. Lunkenheimer (eds.), The Mouton World Atlas of Variation in English. Berlin: Mouton de Gruyter, pp. 197-209.

Eberhardt, M. \& Freeman, K. 2015. "“First things first, I'm the realest": Linguistic appropriation, white privilege, and the hip-hop persona of Iggy Azelea.' Journal of Sociolinguistics, 19(3), 303-327.

Edwards, W. F. 2008. 'African American vernacular English: Phonology.' In E. W. Schneider (ed.), Varieties of English 2: The Americas and the Caribbean. Berlin: Mouton de Gruyter, pp. 181-191.

Gibson, A. 2010. Production and Perception of Vowels in New Zealand Popular Music. Unpublished MPhil dissertation. Auckland, New Zealand: Auckland University of Technology. Online at <http://aut. researchgateway.ac.nz/handle/10292/962> (Accessed January 10, 2016).

Gibson, A. \& Bell, A. 2012. 'Popular music singing as referee design.’ In J. M. Hernández-Campoy \& J. A. Cutillas-Espinosa (eds.), Style-Shifting in Public, pp. 139-164.

Gibsone, H. 2016. 'Talking tactics: Rihanna and the pop stars who change accent.' Online at $<\mathrm{http}$ ://www. theguardian.com/music/2016/feb/04/talk-that-talkrihanna-the-cunning-linguist> (Accessed February 4, 2016).

Hackert, S. 2012. 'Regional profile: The Caribbean.' In B. Kortmann \& K. Lunkenheimer (eds.), The Mouton World Atlas of Variation in English. Berlin: Mouton de Gruyter, pp. 704-33.

Halliday, M. A. K. 1978. Language as Social Semiotic. London: Edward Arnold.

Kortmann, B. \& Lunkenheimer, K. (eds.) 2013. The Electronic World Atlas of Varieties of English. Leipzig: Max Planck Institute for Evolutionary Anthropology. Online at $<\mathrm{http}$ :/ ewave-atlas.org> (Accessed April 29, 2016).

Kretzschmar, W. A. 2008. 'Standard American English pronunciation.' In E. W. Schneider (ed.), Varieties of English 2: The Americas and the Caribbean. Berlin: Mouton de Gruyter, pp. 37-51.

Kreyer, R. 2015. “Funky fresh dressed to impress": A corpus-linguistic view on gender roles in pop songs.' International Journal of Corpus Linguistics, 20(2), 174-204.

Lee, S. J. 2011. 'Globalization of African American vernacular English in popular culture. Blinglish in Korean Hip Hop.' English World-Wide, 32(1), 1-23.

LePage, R. B. \& Tabouret-Keller, A. 1985. Acts of Identity: Creole-based Approaches to Language and Ethnicity. Cambridge: Cambridge University Press.

Mair, C. 2013. 'The World System of Englishes: Accounting for the transnational importance of mobile and mediated vernaculars.' English World-Wide, 34(3), 253-278.

Noelliste, L. 2016. 'Unaware of Jamaican Patois: Critics Blast Rihanna for Speaking "Gibberish" on her New Single "Work".' Online at $<$ http://blackgirllonghair.com/ 2016/02/unaware-of-jamaican-patois-critics-blastrihanna-for-speaking-gibberish-on-her-new-single-work/> (Accessed April 4, 2016).

O’Hanlon, R. 2006. 'Australian Hip Hop: A Sociolinguistic Investigation.' Australian Journal of Linguistics, 26(2), 193-209.

Patrick, P. 2008. 'Jamaican Creole: Morphology and syntax.' In E. W. Schneider (ed.), Varieties of English 2: The Americas and the Caribbean. Berlin: Mouton de Gruyter, pp. 609-644.

Pennycook, A. 2007. Global Englishes. New York: Routledge.

Rihannanow.com. 2016. 'Bio Rihanna.' Online at <http:/ www.rihannanow.com/bio/> (Accessed April 14, 2016).

Roberts, P. A. 2007. West Indians and their Language. Cambridge: Cambridge University Press.

Simpson, P. 1999. 'Language, culture and identity: With (another) look at accents in pop and rock singing.' Multilingua, 18(4), 343-367.

TheCelebFactory. 2012. 'Rihanna on her accent.' Online at $<$ https://www.youtube.com/watch? $\mathrm{v}=5 \mathrm{dnrohN} 4 \mathrm{P} 0 \mathrm{~A}>$. (Accessed February 2, 2016).

Trudgill, P. 1983. 'Acts of conflicting identity: The sociolinguistics of British pop-song performance.' In P. Trudgill (ed.), On Dialect: Social and Geographical Perspectives. Oxford, UK: Blackwell, pp. 141-160.

Wells, J. C. 1982. Accents of English I: An Introduction. Cambridge: Cambridge University Press.

Werner, V. 2012. 'Love is all around: A corpus-based study of pop lyrics.' Corpora, 7(1), 19-50. 
Wolfram, W. 2008. 'Urban African American Vernacular English: Morphology and syntax.' In E. W. Schneider (ed.), Varieties of English 2: The Americas and the Caribbean. Berlin: Mouton de Gruyter, pp. 510-533.

\section{Appendix: Transcription}

The transcription contains four levels. The first level gives an orthographic transcription of the lyrics. The second level presents a phonetic transcription. If the line contains features of CEC or
AAE a third and fourth level of transcription is provided. The third level is a gloss, i.e. an analytical explanation of the individual units of the line. The fourth level is a translation to Standard English. Grammatical information in the gloss is given as abbreviations in small caps: PRO pronoun, SG singular, PL plural, PRO pronoun, s subject, O object, POSS possessive, QUOT quotative, MOD modal, CONJ conjunction, PREP preposition, FUT future, PROG progressive, NEG negation, INDEF indefinite, ART article, $1 / 2 / 3$ person.

\section{[Chorus]}

(1) Work work work work work work

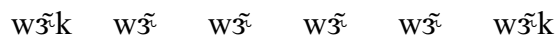

(2) $\mathrm{He}$ se me hafi work work work work work work

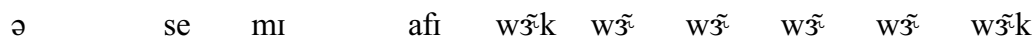
3SG-S-PRO QUOT 1SG-S-PRO MOD work 'he says I have to work'

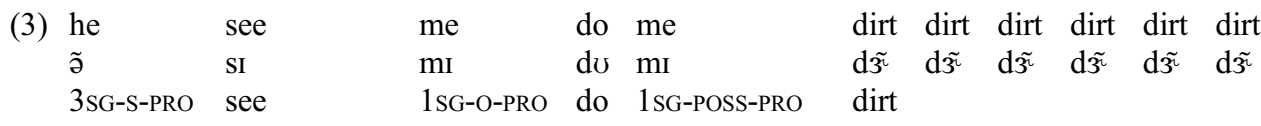
'he sees me doing my dirt'

(4) so me put in sã mI pã? ว̃n

work work work work work work 'so I put in work'

(5) when you a go learn learn learn learn learn learn $\begin{array}{lllllll}\text { wẽn ju ã gã } & 1 \tilde{3} n & 1 \tilde{3} n & 1 \tilde{3} n & 1 \tilde{3} & 1 \tilde{3} & 1 \tilde{3}\end{array}$ when 2SG-S-PRO FUT learn

'when are you going to learn'

(6) Me na care if him hurt hurt hurt hurt hurting

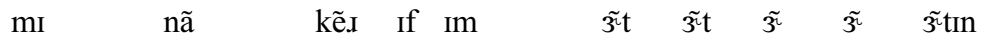
1SG-S-PRO NEG care if 3SG-S-PRO hurt hurt-PROG

'I don't care whether he is hurt'

[Verse 1]

(7) dry

d.rai

me a desert

him no time to

have you

lurking

dry 3SG-S-PRO PROG desert

Im na taim to

hæv jã

$1 \tilde{3}: k ı n$

'I am bored / I am deserting him / I don't have any time to have you hanging around'

lurk-PROG

(8) $\mathrm{Him}$

$$
\text { a go }
$$

act like him

na like it

Im a ga

æ? la:ı? Im

na

lã:ık I?

3SG-S-PRO FUT

act like 3SG-S-PRO NEG like

'he is going to act as if he does not like it' 
(9) You know I dealt with you the nicest

jə no aI del wid jə do na:Isis

'you know I dealt with you in the nicest possible way'

(10) Nobody touch me you na righteous

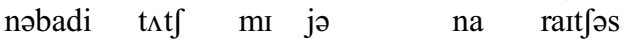

INDEF-PRO touch 3SG-O-PRO 2SG-S-PRO NEG righteous

'nobody touches me / you are not righteous'

(11) No bother text me in a crisis

$\mathrm{Na}$ badə teks $\mathrm{mI}$ In $ə$ k.aIsəs

NEG bother text 3SG-O-PRO PREP INDEF-ART crisis

'don't bother to text me when you are in a crisis'

[Verse 2]

(12) I believed all of your dreams adoration

aI bəliivd al əv jər d.iimz adə.e: $\int a n$

(13) you took my heart and my keys and my patience

jo tok ma:I ha:.t on ma:I ki:z on ma:I pe:fans

(14) you took my heart on my sleeve for decoration

jə tok ma:ı ha:ıt a:n ma:I sli:v fo dekəəe:Jan

(15) you mistaken my love I brought for you for foundation

jə mi'stekən maI ləv aI bıs: fə ju fə faun'de:fan

(16) all that I wanted from you was to give me

al ðæ aI wanəd f.əəm ju wəz tu giv mi:

(17) something that I never had something that you never seen s $\Lambda \mathrm{m} \theta \mathrm{in}$ ठæt as neva hæd s $\Lambda \mathrm{m} \theta \mathrm{In}$ ðæt ju: neva si:n

(18) something that you never been $\mathrm{mh}$

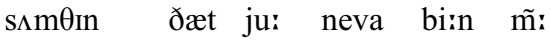

(19) but I wake up and act like nothing's wrong bət al werk $\Lambda \mathrm{p}$ ən æ? la:I nırnz tan

(20) just get ready fi dzos ge? redi fi just get ready PREP 'just get ready to'

[Chorus]

(21) before the tables turn turn turn turn turn turn

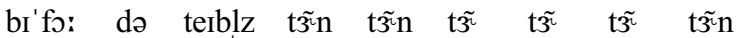

[Verse 3]

(22) beg you something please baby don't you leave beg ju: sım $\theta$ in pli:z berbi doont ju li:v

(23) don't leave me stuck here in the streets uhu doont li:v mi: stək hıə. In ðə st.ıi:ts əhə 
(24) If I get another chance to
If

(25) I Will never no never neglect you a wil nevə no nevə nə'glekt you

(26) I mean who am I to hold your past against you aI mi:n hu: əm aI to hould jər ${ }^{\mathrm{r}}$ pæs əgenst ju:

(27) I Just hope that it gets to you aI dzəst houp ðæt it gets tə ju:

(28) I hope that you see this through aI houp ðæt ju: si: ðIs $\theta$ ru:

(29) I hope that you see this true aI houp ðæt ju: si: ðIs tru:

(30) what can I say please recognize I'm trying babe wat kæn aI seI pli:z rekəgna:z aIm tra:ın berb

(31) I hafi

aI afi

1SG-S-PRO MOD

'I have to'

[Chorus] 